theme 1

theory

author(s) strand 3

aesthetics beyond style
Nazlı Eda Noyan nazlieda.noyan@bahcesehir.edu.tr Bahçeșehir University
Blucher Design Proceedings Dezembro de 2014, Número 5, Volume 1

\title{
What Does This City Say: A Gated Fairy Tale
}

There are numerous studies dealing with the very important question of "what is the impact of graphic language on society", nevertheless this paper addresses a rarely acknowledged area and asks how the graphic language of the logos of gated communities, which are playing a huge role in urban transformation process especially in Istanbul and their brochures printed and distributed for promotion and sales purposes say of these communities. 70 brochures have been examined from the year 2013 with special attention to their graphic language, consisting of repeated symbols as well as slogans such as "a new life" and mostly analogous layouts. Paper argues that this graphic language talk about a future life in the form and with the rhetoric of "fairy tales". Unfortunately, their visual rhetoric seem to lack the diversity, freedom and hence the adventure that a fairy tale and a city promise to offer. In conclusion, the following questions are answered: If we create only the facade but not the content, what kind of a fairy tale do we tell? If we don't express ourselves through design what is its impact on the community? Furthermore, what happens to our language? graphic design, gated communities, identity, fairy tales, visual language

\section{Introduction}

From the window of the public bus, I watch the buildings on top of the hills, thousands of houses, malls and mosques... I see gardens and cars through the impressive and 'privatelysecured' gates of gated communities'. I recall the interesting opinion of a typographer referring to Arabic calligraphy, asserting that the typeface peculiar to a country resembles that country's architectural landscape. Then, is it possible to come up with a graphical language we can attribute with Turkey, that we can call Turkey's? While amusing myself with these thoughts, the billboard ad of a new gated community I see on the roadside suddenly inspires me: What did the graphical representations, site logos and brochures used in the last year (2013), when the boom in gated communities especially in Istanbul was witnessed, 'really' tell to the Istanbulites other than the gated communities they promoted?

In this study the logos of gated communities, as the new members of Istanbul's skyline, and their brochures printed and distributed for promotion and sales purposes will be examined in terms of their graphic languages. The period of the samples to be examined is the year 2013 that has been interesting particularly in terms of being a period where the effects of urbanization were questioned and the effects of projects and sites became even

' Residential areas containing strictly controlled access and often characterized by a closed perimeter of walls and fences. 
theme 1

theory

strand 3

aesthetics beyond style

more apparent in Turkey. All of the 70 samples were taken from the newspaper Hürriyet, which has the largest access to $A B$ and $A B C 1$ groups (upper middle to lower middle class according to socio-economic classification) in Turkey; that is the extension of the new middle class formed in the 1980 s with the effect of the liberal economy in Istanbul and became the consumers of these sites in the $2000 \mathrm{~s}^{2}$.

According to Hollis (1994: 9), logo design is expected to achieve identification where as a brochure has the function of presentation and promotion, besides providing information and guidance by means of the maps and plans it includes. In addition, as the extension of the presentation and promotion functions, persuasion and rhetoric are mentioned. In Bhaba's (Qtd. in Julier 2008: 132) concept of "nation as a narration", nation takes its meaning from language and the rhetoric that sets it forth clearly. However, narration is not independent of objects. On the contrary, even if the narration is based on a context and add meaning, those that are said interact with objects. Visual rhetoric is related with changing the attitude of the audience's understanding and communication concerning the subject in question and its function is to increase audience's awareness on the context of the visual and to create a feeling. Rhetoric is based on one of three methods: Ethos (credibility), logos (logic) and pathos (emotion) qualities of human. The richness of rhetoric may be interpreted as the strength and depth of the expression.

\section{Once Upon A Time: A New Life}

Considering the names of the 70 gated communities examined in the study, in addition to the use of the words such as garden, park, etc. giving reference to nature, the English words of life, village, garden, home and city are frequently used. These names can be explained by the upper classes in Turkey trying to set forth their own identity by possessing Western lifestyle indicators- also highly used by the local dominant media. The traditional architectural terms in Turkish such as yalı, konak, etc. used in these names in the 2000 s and the Ottoman-referenced representations points out to other rising values as the alternative of the West. The prominent visual elements that constitute the primary expression of their logos are trees and leaves, houses and buildings as well as solely typographic and symbolic elements (Figure 1).

Figure 1. Logos for gated communities (2013).
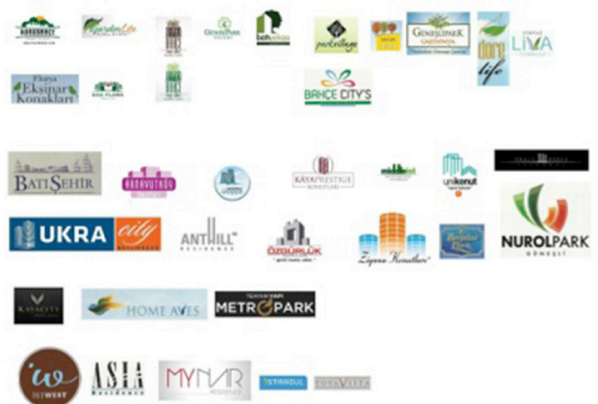

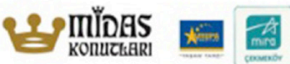

${ }^{2} 35 \%$ of the readers of Hürriyet are from the AB group, while $67 \%$ are from the $A B C_{1}$ S.E.S. group (2012) (Press Monitoring Researches Committee Research September 2011 - August 2012). 
As for the brochures, one can see that nearly all of the representations are made through 3D modelling and presented with photo-collages of humans and nature from different sources. Nearly all of the representations have a clear and sunny ambiance and are isolated from the actual view of the city. With more importance being attached to the sense of reality in 3D modelling, the relation of the building blocks with the city is rendered more unrealistic, and a surreal world is emphasized by the greening and glinting method through the use of decoupage. Almost none of the indoor pictures displaying sample apartments feature people. On the other hand, most of the collages made by 3D modelling have images of people in them. These visuals are usually similar or pixelated photographs obtained from stock image banks. They include sporting, swimming, shopping people, and usually portrayals of happy families with two children in gardens (Fig. 2). The healthy looking, blond or brunette people smiling with white teeth emphasize the modern, western lifestyle just like the buildings. While babies, children and middleaged parents are usually featured in the visuals, elders and adolescents are not common. The nuclear family involved in technology yet also loving the nature is predominantly used in these pictures, in contrast with the traditional extended family or the conservative Turkish family type. References to Ottoman lifestyle can no longer be found except for some architectural elements. The most prominent images are women running on treadmills in gyms, children on grass, poolside, middle-aged people using laptops, airplane, subway, empty sample apartments, security guard. It is also possible to mention the uniformity and the non-diversifying graphic approaches in brochures, as if they come from the same template, with similar typefaces, pictures and frames, circular forms and organic vignettes supporting the typography.

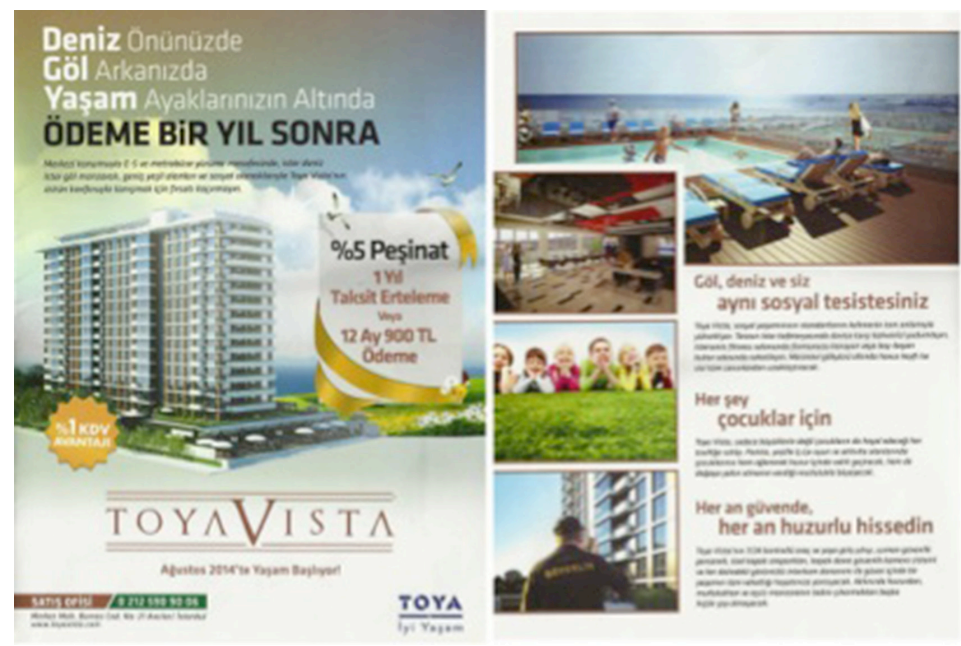

Figure 2. Front cover and inside of a brochure (2013).

In contrast with the slogan themes used for the brochures from the 1980 s and gos such as security, neighbor relations, the prominent themes of today -in the order of their frequency of use- are peace, life, nature; ease of payment; investment value; location; luxury and privilege. The fact that houses, as the essential need for accommodation, can be marketed just like any other consumption material with the visuals and slogans shows that also its consumption is no longer the fulfillment of a need, but a system of choices and possibilities that constitute the recreation of identity and class indicators (such as modern life, old Istanbul architecture, Bosporus view, being close to the nature, etc.). The 
theme 1

theory

Figure 3.

The slogan reads:

"A Life like a fairy

tale has begun".

Brochure front

cover (2013) strand 3

aesthetics beyond style

identities in consumption societies are not determined through personal characteristics but the consumption capacity that indicates the social status (Le Goix, 2003) and create the infrastructure of the marketing of gated communities. Nearly identical gated communities and similar marketing arguments come all together to become an element of prestige. Some of the gated communities are neighbors with the underdeveloped areas where the poor live. This further increases the spatial visibility of social segregation. The isolation in the representations of gated communities emphasize on this segregation and thus privilege by concealing the contrast that remains just out of the gates and guiding us to focus on the building. As the investment value is that prominent, pricing charts in brochures ensure a comparable and easily perceivable communication. While maps -placing emphasis on the location that is once again attributed with investment value and privilege- are included in most of the brochures, apartment plans are featured in only few of them. It is observed that also slogans lay stress on the investment value and the importance of the location, while not mentioning architectural design characteristics. In only one of the samples the architects are included with their names and pictures. From this, we can deduce that while the location is marketable, design is not considered to be marketable.

\section{A Gated Fairy Tale}

Fairy tales, as fictional stories featuring extraordinary elements, a protagonist and events are not based on space and time. They are imaginary and usually told by "taletellers" to groups eager to listen to them. They start and end with a stereotypical nursery rhyme. Similarities and templates are important. The good ones always win. Their creators are anonymous. Are these not very similar with the narration in the marketing of gated communities? Moreover, according to author Gencalp (2014), within this form of expression that has a high dose of "make-believe", lies the desire to believe and to make others believe, regardless of how much of what is being told is true and how much of it is imaginary (Figure 3). These representations of gated communities offer us the final sentence of the fairy tale; "...and they lived happily ever after". Fairy tale protagonists usually start their stories in a place like a forest that invites them to an adventurous journey. Gencalp states that, since the fairy tale-like presentations of gated communities does not make it possible to wander aimlessly and to leave one's self into a flow offering endless diversity, or in other words to be flâneur as Walter Benjamin, this concept of freedom is tried to be made forgotten in gated community representations.

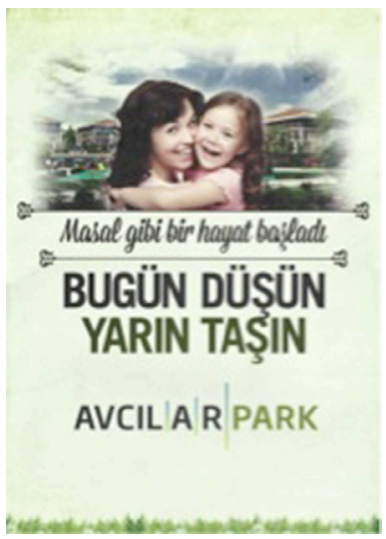


Then, how much does the rhetoric of fairy tales correspond to the visual rhetoric in the logos and brochures of the gated communities in Istanbul that enrich the messages by triggering the reason, emotion and trust of the target population? It's possible to assert that plenty of hyperbole, metaphor and metonymy and some visual pun and personification are being used. Particularly in logos and brochures nature, peace and life without borders are emphasized with the visuals of birds and wings, high quality services and privilege are emphasized through the star symbol, and a privileged life fit for the kings in stories is emphasized through the use of visuals of royal crown. Visuals of gated communities detached and alienated from their environments, and of terrace sceneries rise as the secure castles in fairy tales. In this case, the little princes and princesses are protected by the guards, and they travel with their luxury cars and airplanes. However, this expression that is not really new and unique is somewhat too direct, and therefore remote from the senses of imagination - emotion and trust. While the emphasis on the nature, which replaced the emphasis on security and neighborhood in marketing, is fitting for the narration of a fairy tale, it should be difficult to include the qualities of good investment and ease of payment into the rhetoric of fairy tales.

At this point, it may be fit to mention one of the functions of graphic design; its somewhat mysterious "magic" function. Aumont (Qtd. in Barnard 2005: 15) associates the fact that symbolic images somehow have permission to access the divine area and Kalman (Qtd. in Barnard 2005: 15-16) on the other hand associates the fact that most graphic design represent things different than what they actually are with the magic function. Being built on former agricultural and forest lands on the perimeters of the city, in a way contradicting with the nature emphasize in logos and brochures, gated communities rapidly consume natural reserves with the contributions they make to low density housing, speed of the urban sprawl and a lifestyle dependant on automobiles (Fridin Özgür, 2012: 40); some of the gated communities being marketed through a family-oriented lifestyle are used as bachelor's apartments; and even if gated communities appear to create a neighborhood organization by giving themselves names and identities, it is clear that what is set forth is distant from a real form of neighbourhood organization. In the light of all these, we can assert that there is a degree of misguidance in the representations of gated communities. Furthermore, while the finished states of buildings still under construction are displayed in representations through modelling methods, the more realistic these buildings are modelled the more blurred becomes the actual city, turned into green fields, the city is cut away and "magically" vanishes. Of course the excessive use of the "magic" function may be considered as manipulation, unrealistic or deceptive statement subject to penalties; yet in these brochures the position of the buildings within the city and their views of the city are made different than how they actually are and thus the magic of the fairy tale is fulfilled by offering the consumers "access to the divine area", or in other words a total privilege.

\section{Three Apples: Language, Identity, Design}

Graphic designers -creating the images of these gated communities as the base of the new "fairy tale-like" lives- are anonymous as are the unknown architects. It appears, design is not a very important part of these new lives... With this in consideration, if we turn back to the questions we have asked at the start: A graphic language we can characterize as being Turkey's can only be achieved through a unique, well planned and designed contribution to the urban fabric. Yet it is observed that varying consumer profiles for the marketed gated communities, and different community identities based on different localities are not produced. Marketing of the lifestyle imported from the 
shelves of the global consumption culture does not only standardize and misidentify gated communities, but also Istanbul herself. Julier says, "as we have seen with products, buildings are presented in magazines or brochures via their superficial formal and semantic effects, they're shown as images of themselves (2008: 129). He continues with Pawley suggesting that the implications of breaking away from the canon of appreciation and practice would dispense with the fetishization of external form and embrace internal use. In turn, this will reveal the real import of buildings. And this also applies to graphic design: An anonymous and identity-lacking graphic language where the basic design problem, function and content are overshadowed, can only gain identity and therefore be owned at the extent that the importance of the access to a network that removes the distances is comprehended. Stating "if we assert that the texture (the integrity of climate, geography, architecture, humans, animals, plants and the lifestyle) of each city creates a language, then the loss of the city is the loss of the language", Gencalp asks the question "if language is the instrument of self-expression, a quality that distinguishes humans from other living beings, what is left to us when we lose the language?" This critical question, in fact, is our answer about the basic and important message conveyed to us by the graphic representations of gated communities in Istanbul: Quality design and an urban environment that is livable for all would bring the expectations from graphic design to the very same point.

\section{References}

Barnard, M. (2005) Graphic Design As Communication. Londra: Routledge. Firidin Özgür, E. (2012) "Tüketime Bağlı Bir Kimlik Öğesi Olarak Konut ve Planlama Açısından Bir Değerlendirme", Tasarım + Kuram, No: 14. pp: 29-45 Gençalp, B. (11 January 2014) Personal Interview, İstanbul Hollis, R. (1994) Graphic Design: A Concise History London: Thames \& Hudson Julier, G. (2008) The Culture of Design, London: Sage Le Goix, R. (2003) "Gated communities Sprawl in Southern California and Social Segregation" http://halshs.archives-ouvertes.fr/docs/oo/03/58/67/PDF/legoix20041012.pdf 